Fer ri magnet i c or der i $\mathrm{n}$ the $\mathrm{m}$ xed gar net ( Y1- xGdx) 3Fe5012

\begin{tabular}{|l|l|}
\hline 著者 & $\begin{array}{l}\text { YAMAG SH Takum, AWAKA Junj i , KAWASH NA } \\
\text { Yusuke, EBI SU Shuj i , CH KAZAMA Susum, } \\
\text { NAGATA Shoi chi }\end{array}$ \\
\hline $\begin{array}{l}\text { j our nal or } \\
\text { publ i cat i on t i t l e }\end{array}$ & Phi I osophi cal magazi ne \\
\hline vol ume & 85 \\
\hline number & 17 \\
\hline page range & $1819-1833$ \\
\hline year & $2005-06$ \\
\hline URL & ht t p: //hdl . handl e. net /10258/284 \\
\hline
\end{tabular}


Fer ri magnet i c or der i $\mathrm{n}$ the $\mathrm{m}$ xed gar net ( Y1- xGdx) 3Fe5012

\begin{tabular}{|l|l|}
\hline 著者 & $\begin{array}{l}\text { YAMAG SH Takum, AWAKA Junj i , KAWASH NA } \\
\text { Yusuke, EBI SU Shuj i , CH KAZAMA Susum, } \\
\text { NAGATA Shoi chi }\end{array}$ \\
\hline $\begin{array}{l}\text { j our nal or } \\
\text { publ i cat i on t i t l e }\end{array}$ & Phi I osophi cal magazi ne \\
\hline vol ume & 85 \\
\hline number & 17 \\
\hline page range & $1819-1833$ \\
\hline year & $2005-06$ \\
\hline URL & ht t p: //hdl . handl e. net /10258/284 \\
\hline
\end{tabular}




\title{
Ferrimagnetic order in the mixed garnet $\left\{\mathrm{Y}_{1-x} \mathrm{Gd}_{x}\right\}_{3} \mathrm{Fe}_{5} \mathrm{O}_{12}$
}

\author{
T. Yamagishi, J. Awaka, Y. Kawashima, M. Uemura, \\ S. Ebisu, S. Chikazawa and S. Nagata* \\ Department of Materials Science and Engineering, \\ Muroran Institute of Technology, \\ 27-1 Mizumoto-cho, Muroran, Hokkaido, 050-8585 Japan
}

\begin{abstract}
Ferrimagnetic order in the mixed rare-earth iron garnet $\left\{\mathrm{Y}_{1-x} \mathrm{Gd}_{x}\right\}_{3} \mathrm{Fe}_{5} \mathrm{O}_{12}$ system has been reinvestigated to cover the temperature range 5.0 to $700 \mathrm{~K}$. The magnetization versus temperature exhibits a systematic variation with changing concentration $x$. The ferric-ion exchange coupling is strong enough to determine the Curie temperature $\approx 559 \mathrm{~K}$ for all the values $x$. The compensation temperature at which the magnetization crosses zero (shows the minimum) demonstrates the applicability of the three-sublattice model. The magnetic moment at $5.0 \mathrm{~K}$ indicates reasonable agreement with the relation $n_{\mathrm{B}}=|21 x-5.0| \mu_{\mathrm{B}}$ for the $\left\{\mathrm{Y}_{1-x} \mathrm{Gd}_{x}\right\}_{3} \mathrm{Fe}_{5} \mathrm{O}_{12}$ system. The compensation temperature decreases with decreasing $x$ from 1.0 and reaches zero near $x=$ 0.24. An enlargement of coercive force in the hysteresis loop for the low-field $M-H$ curve is clearly seen in near the compensation temperature, indicating that a single domain is formed and the rotation of this single domain occurs without building up a multidomain structure.
\end{abstract}

\footnotetext{
* Corresponding author. E-mail: naga-sho@mmm.muroran-it.ac.jp
} 


\section{§1. INTRODUCTION}

The general chemical formula of oxide garnets can be written as $\{C\}_{3}[A]_{2}(D)_{3} \mathrm{O}_{12}$, where the $C$-, $A$-, and $D$-sites are the cation sites. These three cation sites are surrounded by oxygen ions $\mathrm{O}^{2-}$ at dodecahedron, octahedron, and tetrahedron positions, respectively. The garnet-type structure has cubic symmetry with space group $I a \overline{3} d$ (No. 230, $O_{h}^{10}$ ) as shown in figure 1 (Geller 1967). The study of garnet compounds has been of great theoretical and experimental interest (Néel et al. 1964, Hellwege 1978).

Since gadolinium-iron garnet $\mathrm{Gd}_{3} \mathrm{Fe}_{5} \mathrm{O}_{12}$ has a high magnetic moment at low temperatures and a compensation temperature of approximately $300 \mathrm{~K}$, much work has been performed (Pauthenet 1956, 1958a). The temperature at which the magnetization crosses zero is called the compensation temperature, $T_{\text {comp. }}$, and this occurs because the magnetization of $\mathrm{Gd}^{3+}$ ion at the $C$-sites is equal and opposite to the net magnetization of $\mathrm{Fe}^{3+}$ ion sublattice at the $A$ - and $D$-sites. On the other hand, the magnetic properties of $\mathrm{Y}_{3} \mathrm{Fe}_{5} \mathrm{O}_{12}$ with a non-magnetic $C$-site has been studied from the view of standard garnet and the Curie temperature is $559 \mathrm{~K}$ (Anderson 1964a).

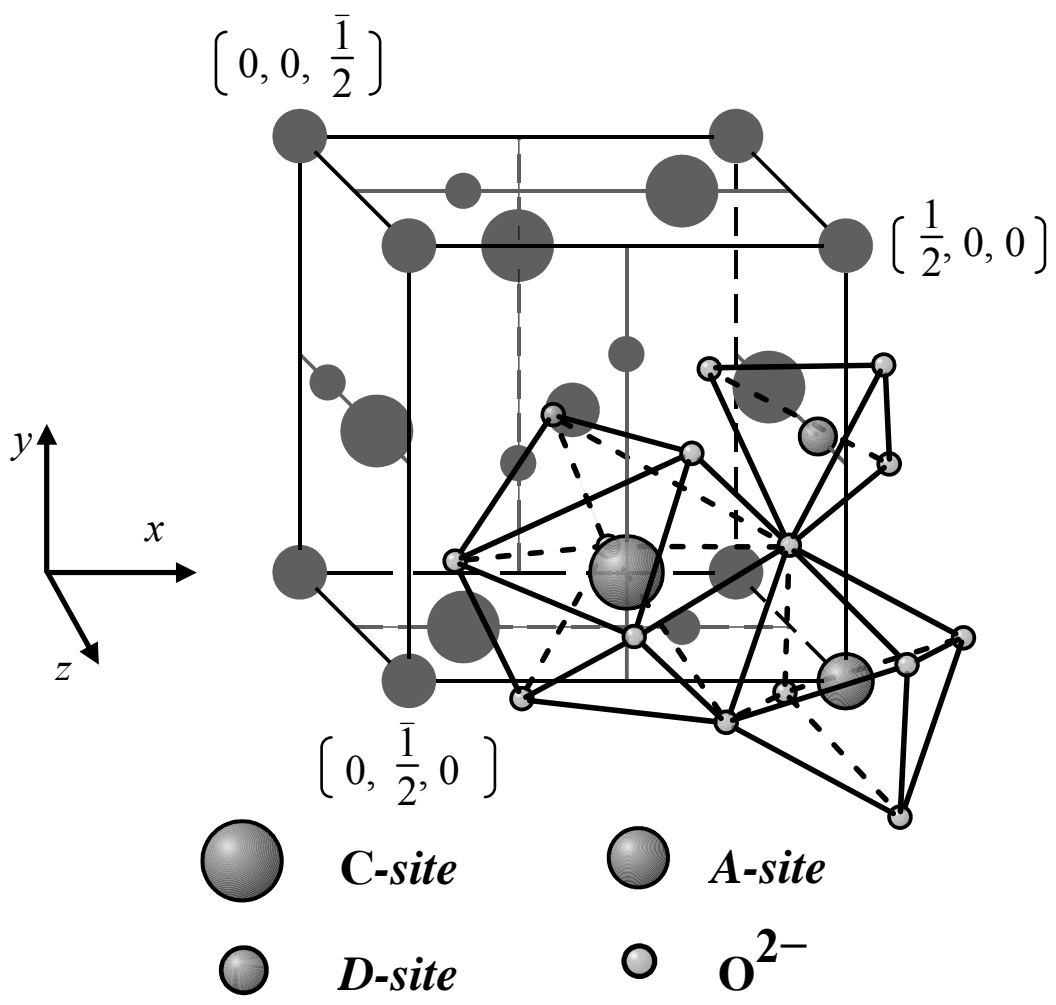

Figure 1. A skeleton drawing of an eighth of unit cell of garnet-type structure $\left\{\mathrm{Y}_{1-x} \mathrm{Gd}_{x}\right\}_{3} \mathrm{Fe}_{5} \mathrm{O}_{12}$ with the dodecahedral $\{C$-site: $\mathrm{Y}$ or $\mathrm{Gd}\}$, octahedral $[A$-site: $\mathrm{Fe}]$, and tetrahedral $(D$-site: $\mathrm{Fe})$ sites, emphasizing the $C$-, $A$ - and $D$-sites. Unit cell of garnet-type structure has the space group Iaj $d$ (No. 230, $O_{h}^{10}$ ). 
The substituted ferrimagnet system $\left\{\mathrm{Y}_{1-x} \mathrm{Gd}_{x}\right\}_{3} \mathrm{Fe}_{5} \mathrm{O}_{12}$ has been extensively investigated in order to examine the effects of gadolinium substitution on the magnetic properties (Anderson et al. 1959, Vassiliev et al. 1961, Harrison and Hodges Jr. 1962, Dionne 1971). However, these magnetic measurements were performed down to only $77 \mathrm{~K}$, and therefore the most significant experimental results below $77 \mathrm{~K}$ were not available. This paper will present the results of fundamental magnetic measurements over the temperature range 5.0 to $700 \mathrm{~K}$, emphasizing the extension to the low-temperature region. This reinvestigation uses very high-purity samples in order to see the variation of the ferrimagnetic order with changing gadolinium concentration $x$. The interest of this system arises because the ionic state of $\mathrm{Gd}^{3+}$ possesses an ${ }^{8} \mathrm{~S}_{7 / 2}$ ground state with a half-filled $4 f$-shell and zero orbital angular momentum $L=0$, which makes it a prime candidate for simple magnetic analysis because the ${ }^{8} \mathrm{~S}_{7 / 2}$ state cannot be split by crystalline electric fields.

\section{§ 2. EXPERIMENTAL METHODS}

The polycrystalline specimens of $\left\{\mathrm{Y}_{1-x} \mathrm{Gd}_{x}\right\}_{3} \mathrm{Fe}_{5} \mathrm{O}_{12}$ were prepared through solid-state chemical reactions:

$$
(3-3 x) \mathrm{Y}_{2} \mathrm{O}_{3}+3 x \mathrm{Gd}_{2} \mathrm{O}_{3}+5 \mathrm{Fe}_{2} \mathrm{O}_{3} \rightarrow 2 \mathrm{Y}_{3-3 x} \mathrm{Gd}_{3 x} \mathrm{Fe}_{5} \mathrm{O}_{12} .
$$

The starting materials, $\mathrm{Y}_{2} \mathrm{O}_{3}$ (purity $99.99 \%$ ), $\mathrm{Gd}_{2} \mathrm{O}_{3}\left(99.99 \%\right.$ ) and $\mathrm{Fe}_{2} \mathrm{O}_{3}(99.9 \%$ ) were mixed in the calculated ratio. Mixed powder materials were put on an alumina boat and heated in a furnace. The temperature was raised to $1723 \mathrm{~K}$ and was held for 4 $\mathrm{h}$ in air. The resultant specimens were reground, and the same temperature sequence was repeated once again.

$\mathrm{X}$-ray powder diffraction (XRD) data were taken at room temperature with $\mathrm{Cu} \mathrm{K} \alpha$ radiation and a curved crystal monochrometer (Graphite with a curvature radius of $224 \mathrm{~mm}$ ) on a Bragg-Brentano-type powder diffractometer. The XRD data were measured in a $2 \theta$ range from 10 to $90 \mathrm{deg}$. with a step interval of $0.02 \mathrm{deg}$. The d.c. magnetization of powder specimens was measured with a Quantum Design superconducting quantum interference device (r.f.-SQUID) magnetometer over a range of $5.0 \leq T \leq 700 \mathrm{~K}$.

\section{§ 3. RESULTS AND DISCUSSION}

\subsection{Crystal structure}

High-purity specimens of $\left\{\mathrm{Y}_{1-x} \mathrm{Gd}_{x}\right\}_{3} \mathrm{Fe}_{5} \mathrm{O}_{12}$ with varying values of $x$ were prepared, and the colour of these powder specimens is dark green. $\mathrm{X}$-ray powder diffraction at room temperature confirms that $\left\{\mathrm{Y}_{1-x} \mathrm{Gd}_{x}\right\}_{3} \mathrm{Fe}_{5} \mathrm{O}_{12}$ has the garnet structure and is single phase for all concentrations of $x$. Three XRD patterns are presented in figure 2 as representative data to confirm the specimen phase purity. The values of the lattice constant $a=12.393 \AA(x=0.20), 12.424 \AA(x=0.50)$, and $12.452 \AA(x=0.80)$ were obtained by the least-square method. The indices, the comparison of $d$ spacings between calculated and observed values, and the observed peak intensities are listed in Tables 1 to 3 . The lattice constants obey Vegard's law with excellent agreement as can be seen in figure 3 . 


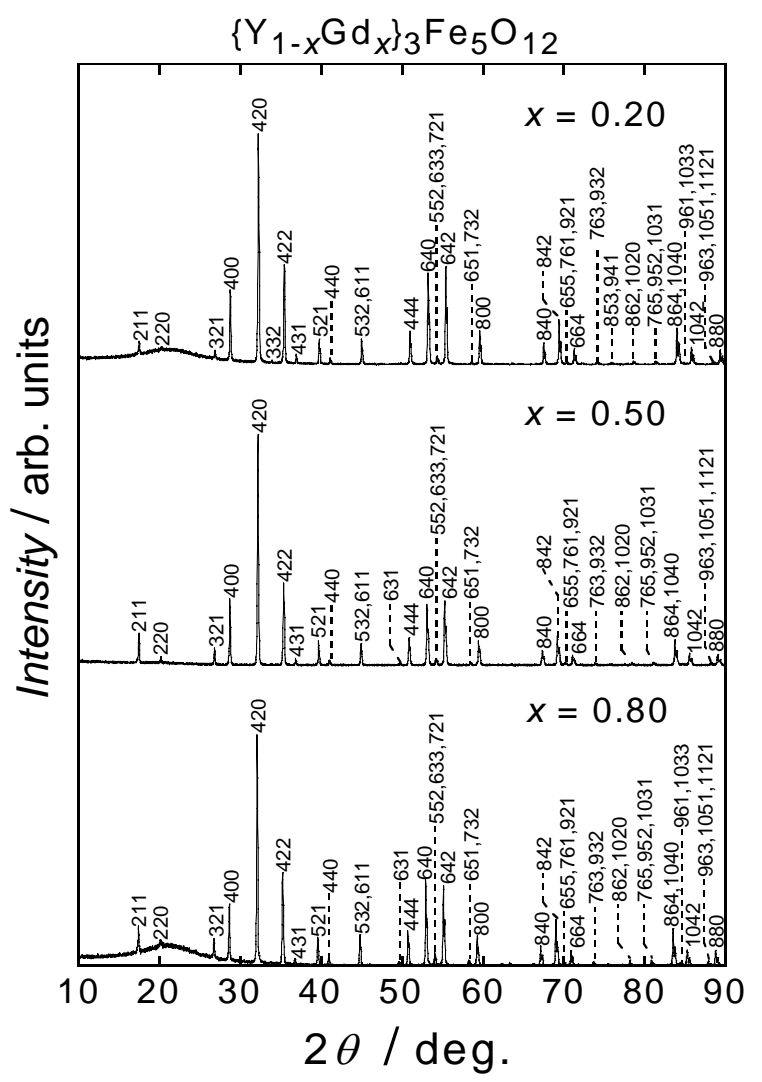

Figure 2. X-ray powder diffraction patterns of $\left\{\mathrm{Y}_{1-x} \mathrm{Gd}_{x}\right\}_{3} \mathrm{Fe}_{5} \mathrm{O}_{12}$ for $x=0.20, \quad 0.50$ and 0.80 at room temperature as representative data. The diffraction peaks can be indexed with cubic symmetry for the garnet-type structure.

\subsection{Temperature dependence of magnetization}

Figure 4 displays the variation of the temperature dependence of the magnetization in Bohr magnetons at an applied field $H=10.0 \mathrm{kOe}$ for polycrystalline specimens of $\left\{\mathrm{Y}_{1-x} \mathrm{Gd}_{x}\right\}_{3} \mathrm{Fe}_{5} \mathrm{O}_{12}$. We note that the values of the magnetization at the compensation temperatures are not completely zero because these values indicate the magnitude of the magnetization at $H=10.0 \mathrm{kOe}$. The magnetic data below $77 \mathrm{~K}$ are the first measurements at low temperatures. The general tendency and aspects of the results are in good agreement with the theoretical predictions calculated in terms of the Néel theory of ferrimagnetism (Anderson 1964b, Dionne 1971). Here we mention simply that we make no comparison of our results with these theories.

The magnetic moment of a $\mathrm{Fe}^{3+}$ ion is $5 \mu_{\mathrm{B}}$, that of a $\mathrm{Y}^{3+}$ ion is zero, and that of a $\mathrm{Gd}^{3+}$ ion is $7 \mu_{\mathrm{B}}$. Per formula unit there are three $\mathrm{Fe}^{3+}$ ions on $D$-sites, two $\mathrm{Fe}^{3+}$ ions on $A$-sites, and three $R^{3+}$ ions $(R=\mathrm{Y}$ or $\mathrm{Gd})$ on $C$-sites. According to Néel, the magnetic properties of $R_{3} \mathrm{Fe}_{5} \mathrm{O}_{12}$ can be explained by assuming that the three-sublattice ferrimagnetism is due to positive $R^{3+}$ spins on $C$-sites, positive $\mathrm{Fe}^{3+}$ spins on $A$-sites and negative $\mathrm{Fe}^{3+}$ spins on $D$-sites. The exchange interaction between $R^{3+}$ ions is almost negligible so that the moment of $R^{3+}$ ions should be aligned by the exchange interaction with the $\mathrm{Fe}^{3+}$ ions. Magnetic moment per formula unit is expressed as, 
Table 1. Indices, observed and calculated values of $d$ spacings and observed peak intensities for $\left\{\mathrm{Y}_{1-x} \mathrm{Gd}_{x}\right\}_{3} \mathrm{Fe}_{5} \mathrm{O}_{12}$ for $x=0.20$ with the lattice constant $a=12.393 \AA$.

\begin{tabular}{|c|c|c|c|c|c|}
\hline$h$ & $k$ & $l$ & $d_{\mathrm{obs}}(\AA)$ & $d_{\text {cal }}(\AA)$ & $I_{\mathrm{obs}}$ \\
\hline 2 & 1 & 1 & 5.0750 & 5.0596 & 5 \\
\hline 2 & 2 & 0 & 4.3967 & 4.3818 & 4 \\
\hline 3 & 2 & 1 & 3.3189 & 3.3123 & 3 \\
\hline 4 & 0 & 0 & 3.1037 & 3.0984 & 29 \\
\hline 4 & 2 & 0 & 2.7743 & 2.7713 & 100 \\
\hline 3 & 3 & 2 & 2.6437 & 2.6423 & 1 \\
\hline 4 & 2 & 2 & 2.5322 & 2.5298 & 45 \\
\hline 4 & 3 & 1 & 2.4327 & 2.4306 & 4 \\
\hline 5 & 2 & 1 & 2.2652 & 2.2627 & 11 \\
\hline 4 & 4 & 0 & 2.1934 & 2.1909 & 3 \\
\hline 5 & 3 & 2 & 2.0120 & 2.0105 & 12 \\
\hline 6 & 1 & 1 & & 2.0105 & \\
\hline 4 & 4 & 4 & 1.7899 & 1.7888 & 16 \\
\hline 6 & 4 & 0 & 1.7197 & 1.7187 & 44 \\
\hline 5 & 5 & 2 & 1.6874 & 1.6865 & 4 \\
\hline 6 & 3 & 3 & & 1.6865 & \\
\hline 7 & 2 & 1 & & 1.6865 & \\
\hline 6 & 4 & 2 & 1.6571 & 1.6561 & 48 \\
\hline 6 & 5 & 1 & 1.5750 & 1.5740 & 1 \\
\hline 7 & 3 & 2 & & 1.5740 & \\
\hline 8 & 0 & 0 & 1.5499 & 1.5492 & 18 \\
\hline 8 & 4 & 0 & 1.3861 & 1.3856 & 11 \\
\hline 8 & 4 & 2 & 1.3527 & 1.3522 & 22 \\
\hline 6 & 5 & 5 & 1.3370 & 1.3364 & 1 \\
\hline 7 & 6 & 1 & & 1.3364 & \\
\hline 9 & 2 & 1 & & 1.3364 & \\
\hline 6 & 6 & 4 & 1.3216 & 1.3211 & 8 \\
\hline 7 & 6 & 3 & 1.2790 & 1.2783 & 1 \\
\hline 9 & 3 & 2 & & 1.2783 & \\
\hline 8 & 5 & 3 & 1.2525 & 1.2519 & 1 \\
\hline 9 & 4 & 1 & & 1.2519 & \\
\hline 8 & 6 & 2 & 1.2159 & 1.2153 & 1 \\
\hline 10 & 2 & 0 & & 1.2153 & \\
\hline 7 & 6 & 5 & 1.1820 & 1.1817 & 2 \\
\hline 9 & 5 & 2 & & 1.1817 & \\
\hline 10 & 3 & 1 & & 1.1817 & \\
\hline 8 & 6 & 4 & 1.1512 & 1.1507 & 18 \\
\hline 10 & 4 & 0 & & 1.1507 & \\
\hline 9 & 6 & 1 & 1.1412 & 1.1409 & 1 \\
\hline 10 & 3 & 3 & & 1.1409 & \\
\hline 10 & 4 & 2 & 1.1318 & 1.1314 & 8 \\
\hline 9 & 6 & 3 & 1.1043 & 1.1041 & 2 \\
\hline 10 & 5 & 1 & & 1.1041 & \\
\hline 11 & 2 & 1 & & 1.1041 & \\
\hline 8 & 8 & 0 & 1.0957 & 1.0954 & 8 \\
\hline
\end{tabular}

$$
M=3 M_{C}+2 M_{A}-3 M_{D} .
$$

For $\mathrm{Y}_{3} \mathrm{Fe}_{5} \mathrm{O}_{12}$, the net magnetization is due to the resultant of two oppositely magnetized $A$ - and $D$-lattices of $\mathrm{Fe}^{3+}$ ions, where the $\mathrm{Y}^{3+}$ ion is non-magnetic. At $T=$ 
0 , each $\mathrm{Fe}^{3+}$ ion saturates and contributes $5 \mu_{\mathrm{B}}$ to the magnetization, which gives $5 \mu_{\mathrm{B}}$ per formula unit.

Table 2. Indices, observed and calculated values of $d$ spacings and observed peak intensities for $\left\{\mathrm{Y}_{1-x} \mathrm{Gd}_{x}\right\}_{3} \mathrm{Fe}_{5} \mathrm{O}_{12}$ for $x=$ 0.50 with the lattice constant $a=12.424 \AA$.

\begin{tabular}{|c|c|c|c|c|c|}
\hline$h$ & $k$ & $l$ & $d_{\mathrm{obs}}(\AA)$ & $d_{\mathrm{cal}}(\AA)$ & $I_{\mathrm{obs}}$ \\
\hline 2 & 1 & 1 & 5.0808 & 5.0721 & 11 \\
\hline 2 & 2 & 0 & 4.3967 & 4.3925 & 3 \\
\hline 3 & 2 & 1 & 3.3238 & 3.3205 & 7 \\
\hline 4 & 0 & 0 & 3.1079 & 3.1060 & 28 \\
\hline 4 & 2 & 0 & 2.7810 & 2.7781 & 100 \\
\hline 4 & 2 & 2 & 2.5377 & 2.5360 & 38 \\
\hline 4 & 3 & 1 & 2.4378 & 2.4365 & 3 \\
\hline 5 & 2 & 1 & 2.2696 & 2.2683 & 10 \\
\hline 4 & 4 & 0 & 2.1985 & 2.1963 & 2 \\
\hline 5 & 3 & 2 & 2.0162 & 2.0154 & 11 \\
\hline 6 & 1 & 1 & & 2.0154 & \\
\hline 6 & 3 & 1 & 1.8329 & 1.8318 & 1 \\
\hline 4 & 4 & 4 & 1.7938 & 1.7932 & 14 \\
\hline 6 & 4 & 0 & 1.7233 & 1.7229 & 31 \\
\hline 5 & 5 & 2 & 1.6915 & 1.6907 & 3 \\
\hline 6 & 3 & 3 & & 1.6907 & \\
\hline 7 & 2 & 1 & & 1.6907 & \\
\hline 6 & 4 & 2 & 1.6609 & 1.6602 & 34 \\
\hline 6 & 5 & 1 & 1.5784 & 1.5778 & 1 \\
\hline 7 & 3 & 2 & & 1.5778 & \\
\hline 8 & 0 & 0 & 1.5533 & 1.5530 & 12 \\
\hline 8 & 4 & 0 & 1.3894 & 1.3890 & 7 \\
\hline 8 & 4 & 2 & 1.3562 & 1.3556 & 15 \\
\hline 6 & 5 & 5 & 1.3399 & 1.3397 & 1 \\
\hline 7 & 6 & 1 & & 1.3397 & \\
\hline 9 & 2 & 1 & & 1.3397 & \\
\hline 6 & 6 & 4 & 1.3248 & 1.3244 & 4 \\
\hline 7 & 6 & 3 & 1.2817 & 1.2814 & 1 \\
\hline 9 & 3 & 2 & & 1.2814 & \\
\hline 8 & 6 & 2 & 1.2187 & 1.2183 & 1 \\
\hline 10 & 2 & 0 & & 1.2183 & \\
\hline 7 & 6 & 5 & 1.1851 & 1.1846 & 1 \\
\hline 9 & 5 & 2 & & 1.1846 & \\
\hline 10 & 3 & 1 & & 1.1846 & \\
\hline 8 & 6 & 4 & 1.1539 & 1.1535 & 13 \\
\hline 10 & 4 & 0 & & 1.1535 & \\
\hline 10 & 4 & 2 & 1.1343 & 1.1342 & 5 \\
\hline 9 & 6 & 3 & 1.1067 & 1.1068 & 1 \\
\hline 10 & 5 & 1 & & 1.1068 & \\
\hline 11 & 2 & 1 & & 1.1068 & \\
\hline 8 & 8 & 0 & 1.0984 & 1.0981 & 5 \\
\hline
\end{tabular}

Table 3. Indices, observed and calculated values of $d$ spacings and observed peak intensities for $\left\{\mathrm{Y}_{1-x} \mathrm{Gd}_{x}\right\}_{3} \mathrm{Fe}_{5} \mathrm{O}_{12}$ for $x=$ 0.80 with the lattice constant $a=12.452 \AA$.

\begin{tabular}{cccccr}
\hline$h$ & $k$ & $l$ & $d_{\text {obs }}(\AA)$ & $d_{\text {cal }}(\AA)$ & $I_{\text {obs }}$ \\
\hline 2 & 1 & 1 & 5.0982 & 5.0835 & 11 \\
2 & 2 & 0 & 4.4140 & 4.4024 & 6 \\
3 & 2 & 1 & 3.3336 & 3.3279 & 8 \\
4 & 0 & 0 & 3.1164 & 3.1130 & 23 \\
4 & 2 & 0 & 2.7878 & 2.7844 & 100 \\
4 & 2 & 2 & 2.5447 & 2.5418 & 41 \\
4 & 3 & 1 & 2.4442 & 2.4420 & 3 \\
5 & 2 & 1 & 2.2762 & 2.2734 & 13 \\
4 & 4 & 0 & 2.2036 & 2.2012 & 3 \\
5 & 3 & 2 & 2.0214 & 2.0200 & 15 \\
6 & 1 & 1 & & 2.0200 & \\
6 & 3 & 1 & 1.8378 & 1.8359 & 2 \\
4 & 4 & 4 & 1.7984 & 1.7973 & 17 \\
6 & 4 & 0 & 1.7281 & 1.7268 & 41 \\
5 & 5 & 2 & 1.6955 & 1.6945 & 6 \\
6 & 3 & 3 & & 1.6945 & \\
7 & 2 & 1 & & 1.6945 & \\
6 & 4 & 2 & 1.6648 & 1.6640 & 39 \\
6 & 5 & 1 & 1.5824 & 1.5814 & 2 \\
7 & 3 & 2 & & 1.5814 & \\
8 & 0 & 0 & 1.5575 & 1.5565 & 15 \\
8 & 4 & 0 & 1.3927 & 1.3922 & 9 \\
8 & 4 & 2 & 1.3593 & 1.3586 & 23 \\
6 & 5 & 5 & 1.3433 & 1.3427 & 2 \\
7 & 6 & 1 & & 1.3427 & \\
9 & 2 & 1 & & 1.3427 & \\
6 & 6 & 4 & 1.3278 & 1.3274 & 8 \\
7 & 6 & 3 & 1.2847 & 1.2843 & 2 \\
9 & 3 & 2 & & 1.2843 & \\
8 & 6 & 2 & 1.2214 & 1.2210 & 2 \\
10 & 2 & 0 & & 1.2210 & \\
7 & 6 & 5 & 1.1878 & 1.1873 & 2 \\
9 & 5 & 2 & & 1.1873 & \\
10 & 3 & 1 & & 1.1873 & \\
8 & 6 & 4 & 1.1566 & 1.1561 & 19 \\
10 & 4 & 0 & & 1.1561 & \\
9 & 6 & 1 & 1.1467 & 1.1463 & 1 \\
10 & 3 & 3 & & 1.1463 & \\
10 & 4 & 2 & 1.1371 & 1.1367 & 8 \\
9 & 6 & 3 & 1.1097 & 1.1093 & 2 \\
10 & 5 & 1 & & 1.1093 & \\
11 & 2 & 1 & & 1.1093 & \\
\hline & 8 & 0 & 1.1009 & 1.1006 & 8 \\
\hline & & & & &
\end{tabular}




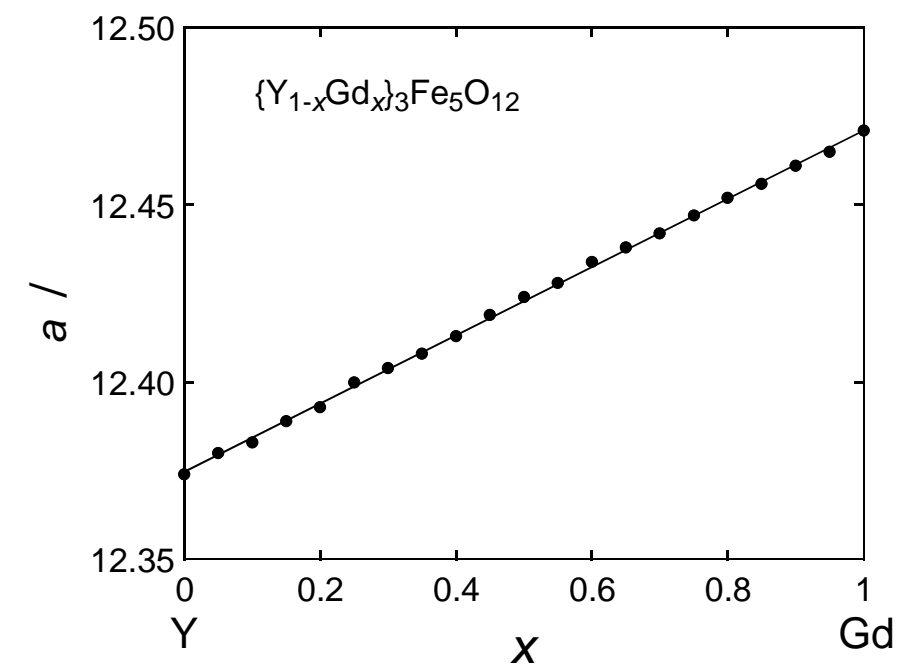

Figure 3. Lattice constants of $\left\{\mathrm{Y}_{1-x} \mathrm{Gd}_{x}\right\}_{3} \mathrm{Fe}_{5} \mathrm{O}_{12}$ at room temperature for Y-Gd solid solution. The solid line indicates the Vegard's law, where these experimental results depend linearly on the concentration $x$.

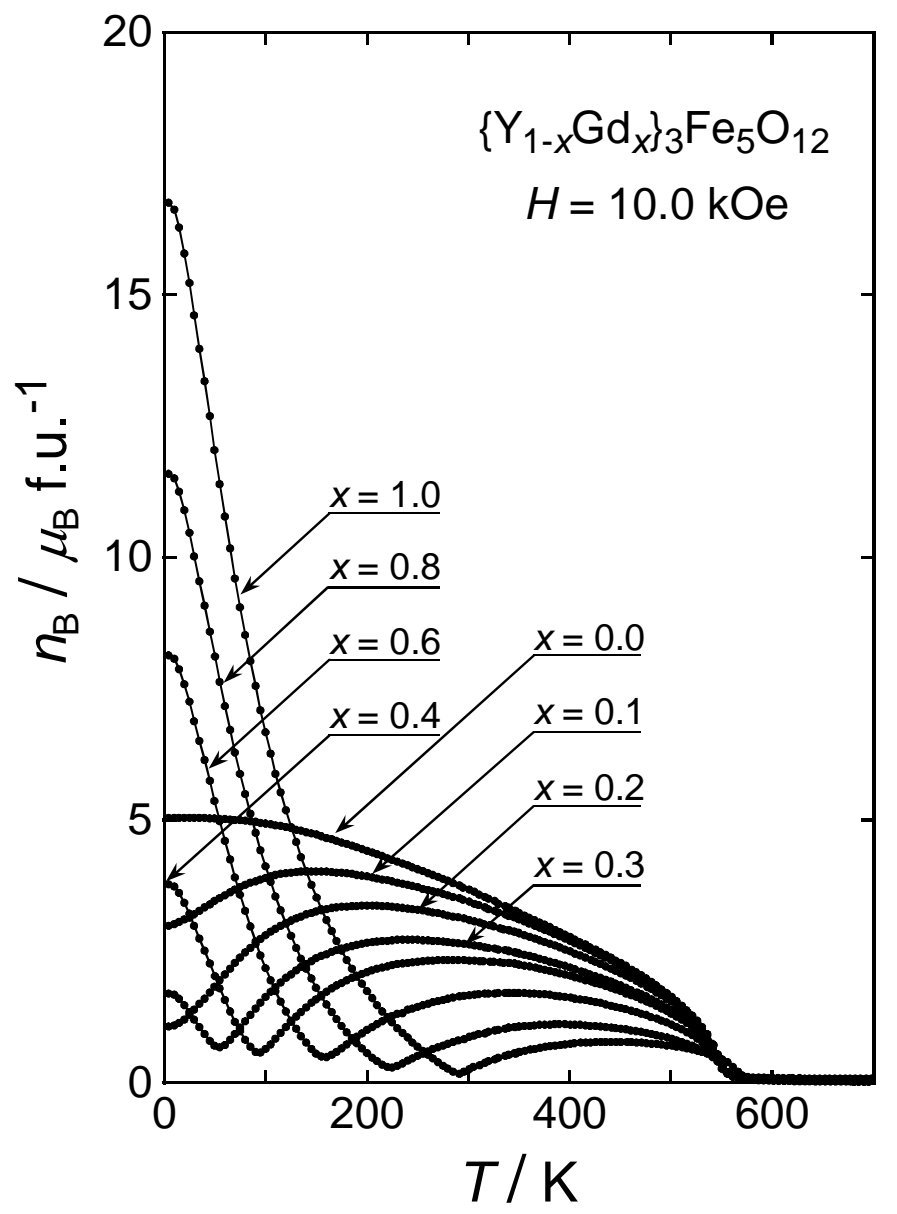

Figure 4. Magnetization versus temperature for $\left\{\mathrm{Y}_{1-x} \mathrm{Gd}_{x}\right\}_{3} \mathrm{Fe}_{5} \mathrm{O}_{12}$ in Bohr magnetons per formula unit at constant magnetic field of $10.0 \mathrm{kOe}$. 
For $\mathrm{Gd}_{3} \mathrm{Fe}_{5} \mathrm{O}_{12}$, the ferric ions contribute $(3-2) \times 5 \mu_{\mathrm{B}}=5 \mu_{\mathrm{B}}$ per formula unit. The ferric-ion magnetic coupling is strong and determines the Curie temperature of $559 \mathrm{~K}$. The $\mathrm{Gd}^{3+}$ ions are magnetized opposite to the net magnetization of the $\mathrm{Fe}^{3+}$ ions on the $A+D$ sites. At low temperatures, the combined moments of the three $\mathrm{Gd}^{3+}$ ions in the formula unit dominate the net moment of the $\mathrm{Fe}^{3+}$ ions. At $T=0$, $\mathrm{Gd}_{3} \mathrm{Fe}_{5} \mathrm{O}_{12}$ gives $16 \mu_{\mathrm{B}}$ per formula unit. Since the $C$ - $A$ and $C-D$ magnetic couplings are weak, $\mathrm{Gd}^{3+}$ ions on the $C$-lattice lose their magnetization rapidly with increasing temperature. The total moment can pass through zero and then increase again as the $\mathrm{Fe}^{3+}$ moments start to be dominant.

The mixed crystal system $\left\{\mathrm{Y}_{1-x} \mathrm{Gd}_{x}\right\}_{3} \mathrm{Fe}_{5} \mathrm{O}_{12}$ can be understood as the superposition of $\mathrm{Y}_{3} \mathrm{Fe}_{5} \mathrm{O}_{12}$ and $\mathrm{Gd}_{3} \mathrm{Fe}_{5} \mathrm{O}_{12}$. The molecular-field coefficients for $\left\{\mathrm{Y}_{1-x} \mathrm{Gd}_{x}\right\}_{3} \mathrm{Fe}_{5} \mathrm{O}_{12}$ are calculated by fitting the experimental data obtained above 77 K (Anderson 1964b, Dionne 1971).

We present the following simple experiment to understand the reversal of the total magnetization direction at the compensation temperature as demonstrated in figure 5. The magnetization disappears at the compensation temperature where it changes sign. The sintered specimen of $\left\{\mathrm{Y}_{1-x} \mathrm{Gd}_{x}\right\}_{3} \mathrm{Fe}_{5} \mathrm{O}_{12}$ had a volume $2 \times 2 \times 20 \mathrm{~mm}^{3}$ and $x=$ 0.70 . This specimen has a compensation temperature with of approximately $190 \mathrm{~K}$. It was hung by a thread knotted at the center of gravity so that it could swing freely horizontally. The specimen was dipped in liquid nitrogen and cooled to $77 \mathrm{~K}$. Next this specimen was moved by the hanging thread to just above a small horseshoe-shaped magnet, a child's toy. The specimen was magnetized between the two $\mathrm{N}$ - and S-poles by the U-shape magnet, with long axis parallel to magnetic field. As temperature rose slowly from 77 to $300 \mathrm{~K}$ in air, the sample rotated through 180 degrees horizontally toward the opposite pole of the magnet at approximately the compensation temperature $190 \mathrm{~K}$. It took approximately 5 minutes to demonstrate this slow motion experiment to students. On the other hand, the reversing the sequence of experimental process on cooling could also exhibit the rotation of the specimen on passing the $T_{\text {comp. }}$.

Table 4. Summary of numerical value concerning the compensation temperature $T_{\text {comp. for }}\left\{\mathrm{Y}_{1-x} \mathrm{Gd}_{x}\right\}_{3} \mathrm{Fe}_{5} \mathrm{O}_{12}$. The magnitude of the magnetization per formula unit at $T_{\text {comp. }}$ in $10.0 \mathrm{kOe}$ also listed.

\begin{tabular}{ccc}
\hline Gd concentration & compensation temperature & $\begin{array}{c}\text { magnetization at } T_{\text {comp. }} \text { in } 10.0 \text { kOe } \\
x\end{array}$ \\
$T_{\text {comp. }}(\mathrm{K})$ & $M(\mathrm{emu} /$ mol-f.u. $)$ \\
\hline 0.30 & 55 & 3800 \\
0.40 & 95 & 3230 \\
0.50 & 130 & 4790 \\
0.60 & 160 & 2740 \\
0.70 & 190 & 3020 \\
0.80 & 225 & 1670 \\
0.90 & 250 & 1740 \\
1.00 & 291 & 960 \\
\hline
\end{tabular}




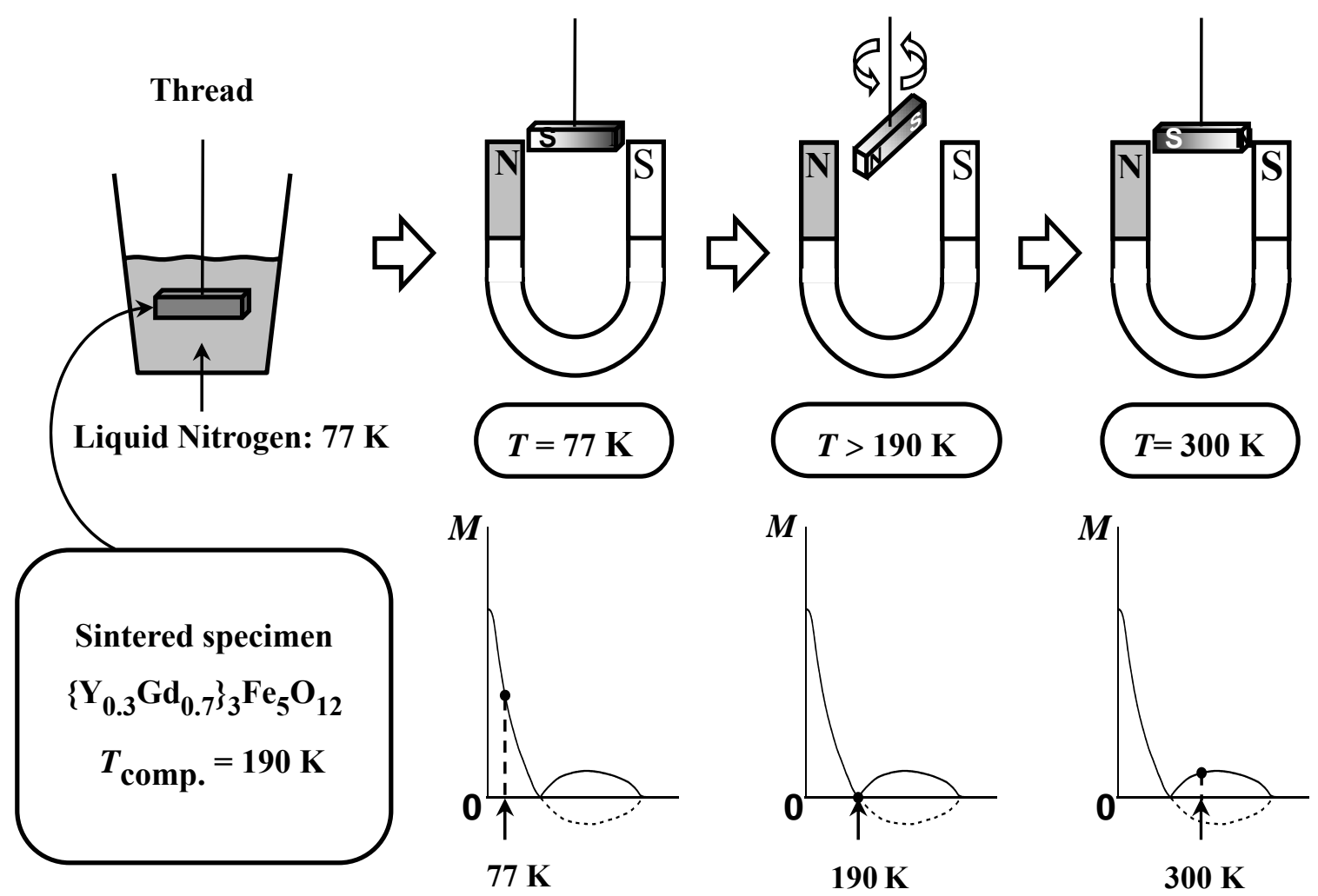

Figure 5. Demonstration of reversal of magnetization direction at the compensation temperature at $190 \mathrm{~K}$, by using the sintered rectangular specimen of $\left\{\mathrm{Y}_{1-x} \mathrm{Gd}_{x}\right\}_{3} \mathrm{Fe}_{5} \mathrm{O}_{12}$ for $x=0.70$, see text.

\subsection{Magnetic susceptibility above $T_{\mathrm{C}}$}

Figure 6 shows the variation of the temperature dependence of the reciprocal magnetic susceptibility $\chi^{-1}$ at $H=10.0 \mathrm{kOe}$ for $\left\{\mathrm{Y}_{1-x} \mathrm{Gd}_{x}\right\}_{3} \mathrm{Fe}_{5} \mathrm{O}_{12}$. The temperature $700 \mathrm{~K}$, which is the maximum measured, was not high enough to express the reciprocal susceptibility in order to catch the whole characteristics of the ferrimagnetism for the temperature dependence above the Curie temperature. Since the Curie temperature is $559 \mathrm{~K}$, the measurements at much higher temperatures than $700 \mathrm{~K}$ are needed. The qualitative variation of the reciprocal susceptibility, nevertheless, reflects manifestly ferrimagnetism (Pauthenet 1958b, Aléonard 1960). The $\chi^{-1}$ versus $T$ curves deviate from the asymptotic line and finally drop off to zero near the ferromagnetic Curie temperature $559 \mathrm{~K}$. Nevertheless, note that the asymptotic extrapolation of the $\chi^{-1}$ versus $T$ curve is different from the simple two-sublattice ferrimagnetic model because of the existence of three-sublattice in this system $\left\{\mathrm{Y}_{1-x} \mathrm{Gd}_{x}\right\}_{3} \mathrm{Fe}_{5} \mathrm{O}_{12}$.

\subsection{M-H curves at constant temperature}

Figures 7 to 11 present the magnetization curves up to $10.0 \mathrm{kOe}$ for $\left\{\mathrm{Y}_{1-x} \mathrm{Gd}_{x}\right\}_{3} \mathrm{Fe}_{5} \mathrm{O}_{12}$. The scale of the vertical axis is different in each of these figures. 
All of the magnetization curves show reasonable agreement with the results of figure 4. It is noteworthy that figure $10\left(M-H\right.$ curve for $\left.\mathrm{Gd}_{3} \mathrm{Fe}_{5} \mathrm{O}_{12}\right)$ shows an enlarged area in the hysteresis loop with large coercive force in the low-field $M-H$ curve near the compensation temperature, $T_{\text {comp. }}$, in contrast to other temperatures. It should be noted that the $M-H$ curve at $T_{\text {comp. }}=291 \mathrm{~K}$ shows an almost straight line without hysteresis, while the $M-H$ curves at $280 \mathrm{~K}$ and $300 \mathrm{~K}$ show pronounced hysteresis loops in the low fields, as can be seen in figure 10. The same behaviour is seen in the $M-H$ curve at $100 \mathrm{~K}$ for $x=0.40\left(T_{\text {comp. }} \approx 95.1 \mathrm{~K}\right)$ in figure 11 . The enlargement of coercive force in the hysteresis loop in low-magnetic fields requires a more precise study in the vicinity of the compensation temperature $T_{\text {comp. }}$, which will be discussed into details elsewhere by present authors in the future. The resultant spontaneous magnetization tends to zero at $T_{\text {comp. }}$, then near $T_{\text {comp. }}$ the formation of a single domain is much easier without large increase of magnetostatic energy. The observed anomalous coercive force indicates that a single domain is formed without making up a multidomain structure and the rotation of this single domain occurs rather than domain wall displacement of a multidomain structure. This observation can be applied to determine accurately the compensation temperature by using a lower field $M-H$ curve.

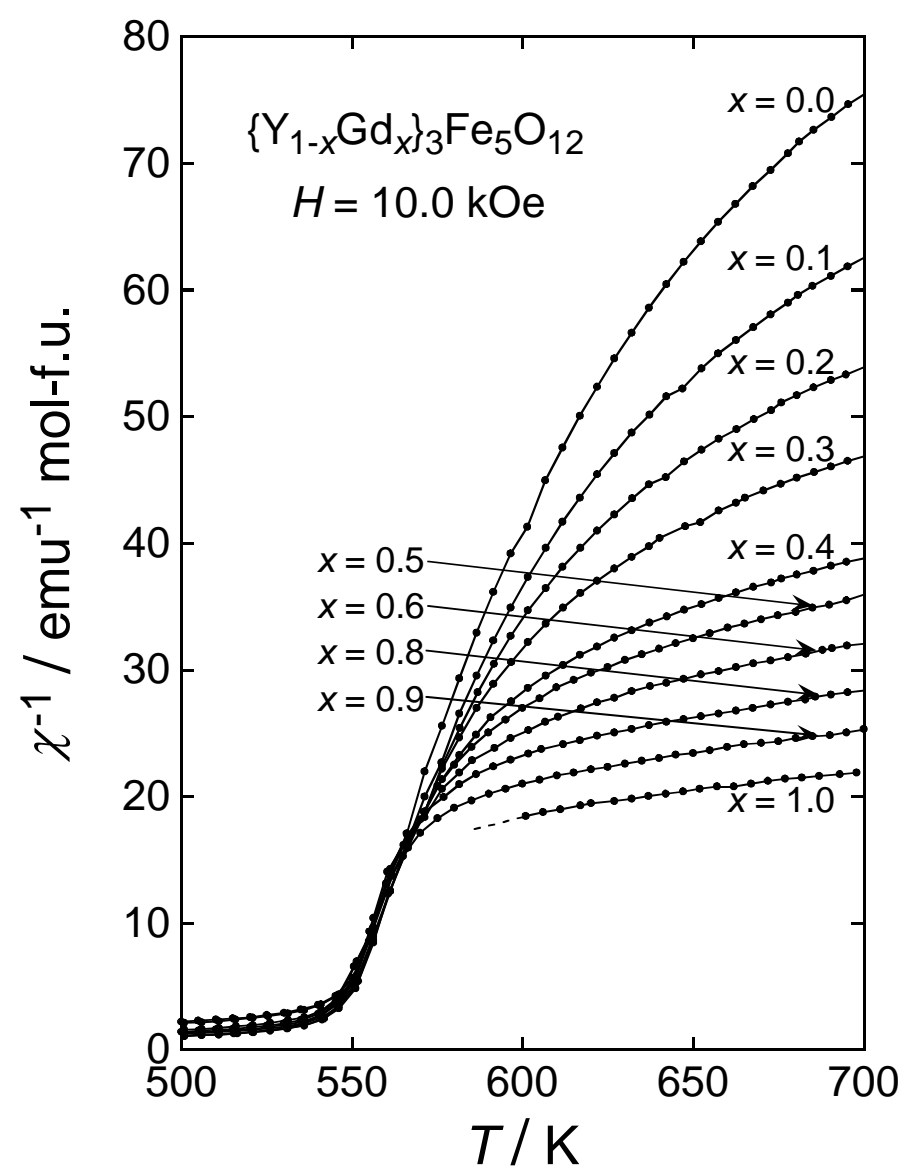

Figure 6. Variation of the reciprocal magnetic susceptibility $\chi^{-1}=(M / H)^{-1}$ versus temperature for $\left\{\mathrm{Y}_{1-x} \mathrm{Gd}_{x}\right\}_{3} \mathrm{Fe}_{5} \mathrm{O}_{12}$, above Curie temperature in a constant field of $10.0 \mathrm{kOe}$. 


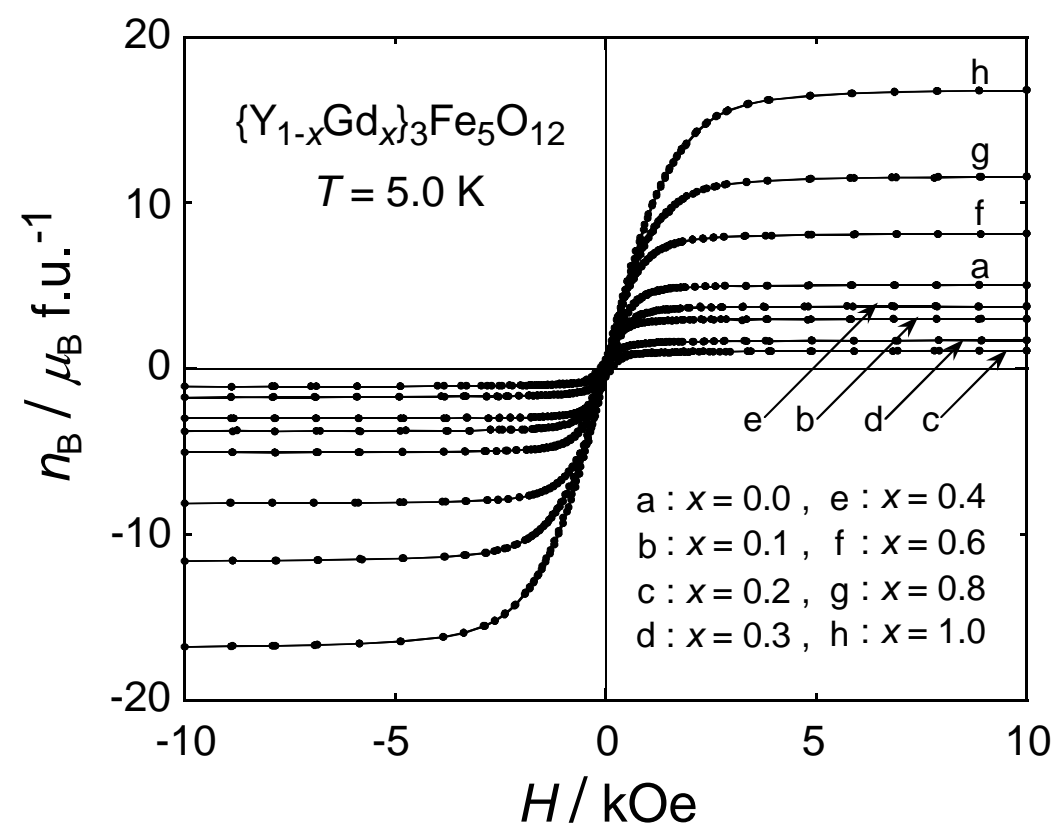

Figure 7. Magnetization curves for $\left\{\mathrm{Y}_{1-x} \mathrm{Gd}_{x}\right\}_{3} \mathrm{Fe}_{5} \mathrm{O}_{12}$ at $5.0 \mathrm{~K}$ up to magnetic field $10.0 \mathrm{kOe}$.

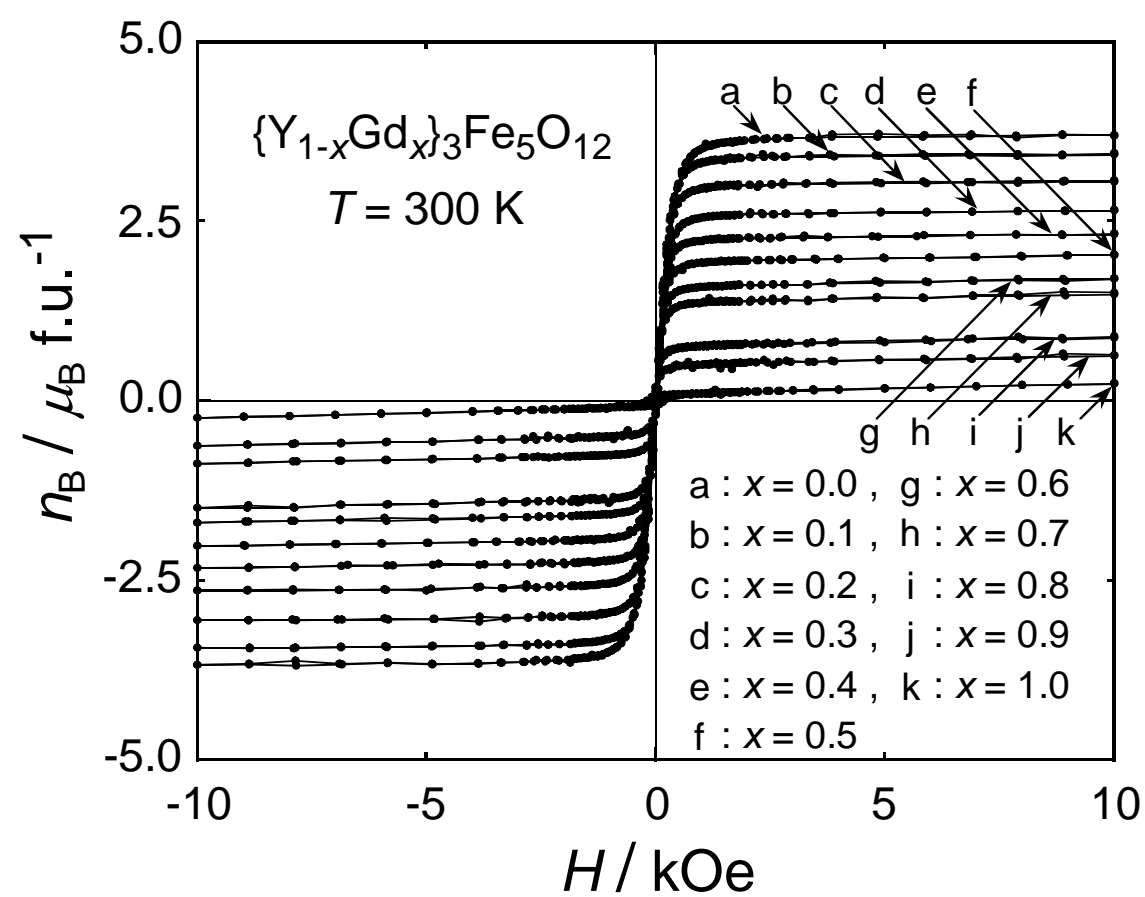

Figure 8. Magnetization curves for $\left\{\mathrm{Y}_{1-x} \mathrm{Gd}_{x}\right\}_{3} \mathrm{Fe}_{5} \mathrm{O}_{12}$ at $300 \mathrm{~K}$ up to magnetic field $10.0 \mathrm{kOe}$. 

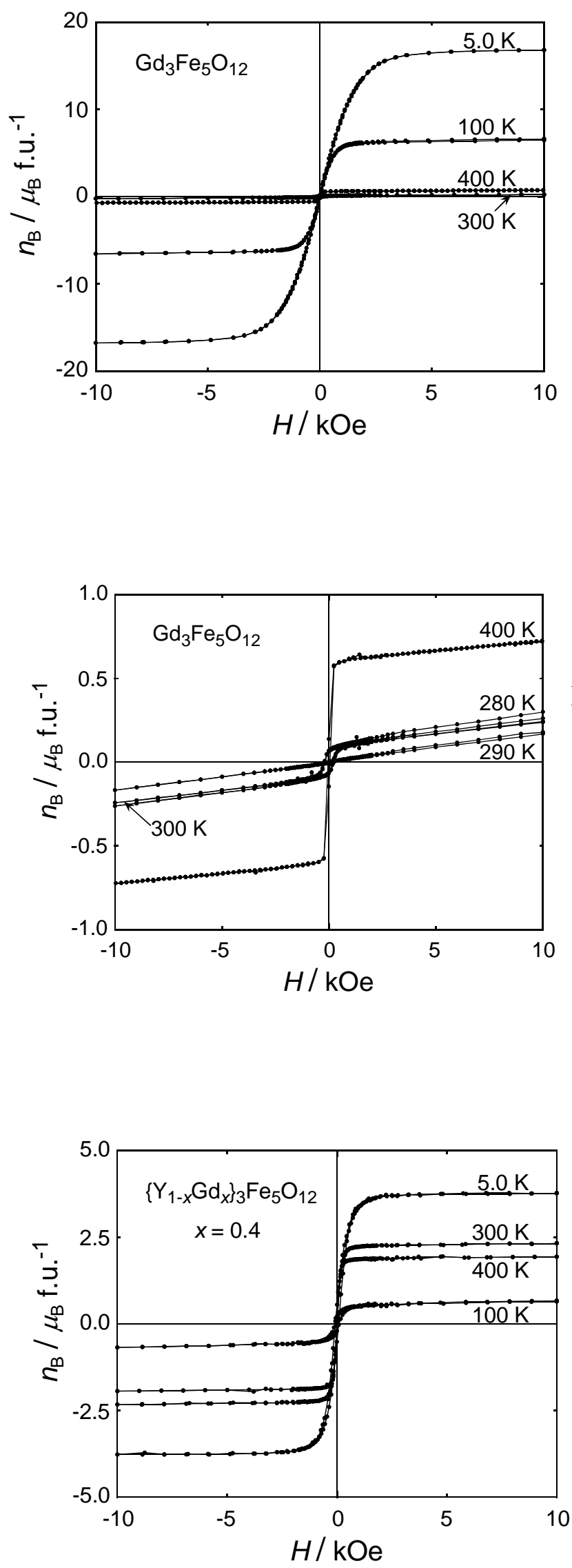

Figure 9. Temperature dependence of the magnetization curves for $\mathrm{Gd}_{3} \mathrm{Fe}_{5} \mathrm{O}_{12}$ for several temperatures.
Figure 10. Temperature dependence of the magnetization curves for $\mathrm{Gd}_{3} \mathrm{Fe}_{5} \mathrm{O}_{12}$ for the several temperatures close to the compensation temperature.
Figure 11. Temperature dependence of the magnetization curves for $\left\{\mathrm{Y}_{1-x} \mathrm{Gd}_{x}\right\}_{3} \mathrm{Fe}_{5} \mathrm{O}_{12}$ for $x=0.40$ for the several temperatures. 
Figure 12 illustrates the relationship between the $M-H$ curve and the temperature variation of the maximum magnetization at $5.0 \mathrm{~K}$ in $10.0 \mathrm{kOe}$. The magnitude of the magnetization is expressed in units of magnetic moment per formula unit along the longitudinal axis. These values at $5.0 \mathrm{~K}$ show oscillatory behaviour with changing $x$. The temperature dependence of the magnetization is well understood in terms of the three-sublattice ferrimagnetism mentioned above.

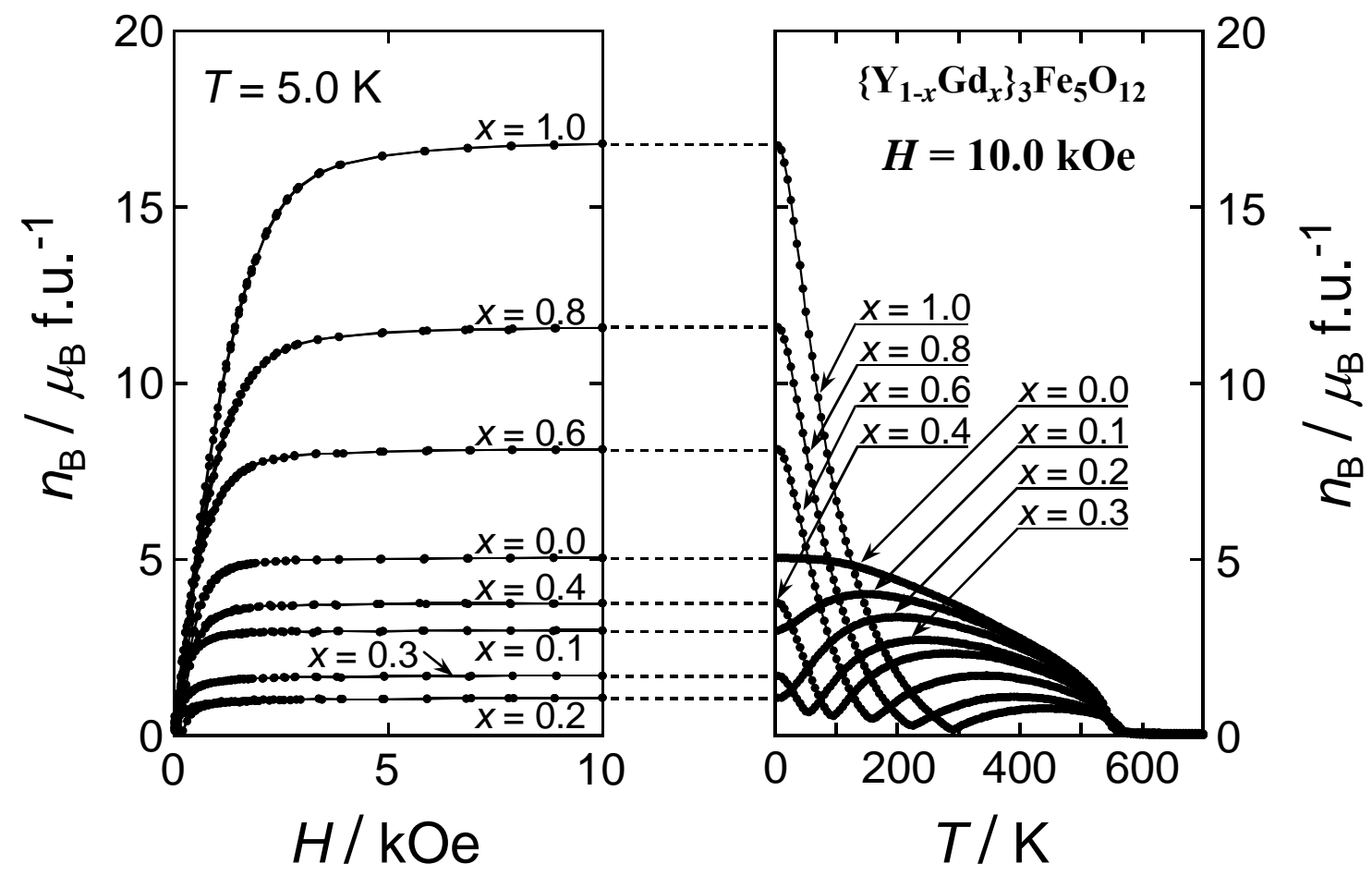

Figure 12. Relationship between magnetization curves at $5.0 \mathrm{~K}$ and the temperature dependence of the magnetization at $10.0 \mathrm{kOe}$.

\subsection{Concentration dependence of the magnetic moments at $5.0 \mathrm{~K}$}

Figure 13 indicates the saturation magnetization versus concentration $x$ at $5.0 \mathrm{~K}$ in $10.0 \mathrm{kOe}$. Anderson et al. (1959) presented the data at $77 \mathrm{~K}$, while we have shown the results at $5.0 \mathrm{~K}$. The experimental values are indicated by solid circles. The straight two lines of a $\mathrm{V}$-shape show a relation given as,

$$
n_{\mathrm{B}}=|21 x-5.0| \mu_{\mathrm{B}},
$$

where the value of $n_{\mathrm{B}}$ is $5.0 \mu_{\mathrm{B}}$ for $x=0$ and $16.0 \mu_{\mathrm{B}}$ for $x=1.0$. This low-temperature result had not been previously available. The value of zero is expected for $x=0.24$, as seen in figure 13. These results are reasonable on the basis of three-sublattice ferrimagnetim. 


\subsection{Concentration dependence of the compensation temperature}

Figure 14 indicates the concentration dependence of the compensation temperature. The theoretical calculation are by Anderson, and the experimental values for all the garnets of the Y-Gd mixed system are in excellent agreement with the improved molecular field calculations (Anderson 1964b). The compensation temperatures decrease linearly with decreasing $x$ from 1.0 to $\approx 0.4$, and then they deviate from linearity and drop off to zero around $x=0.24$.

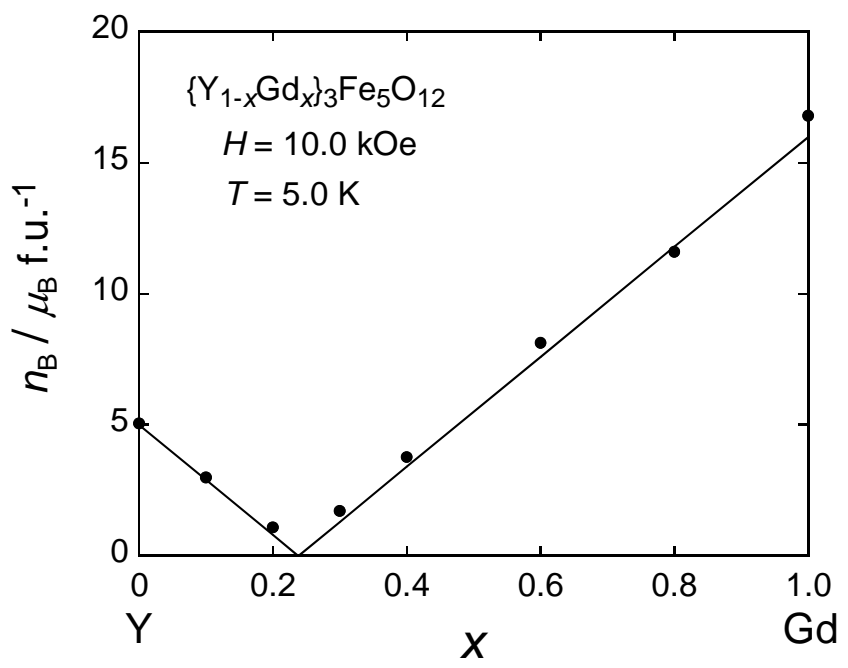

Figure 13. Concentration dependence of the magnetic moment per formula unit at $5.0 \mathrm{~K}$ for $\left\{\mathrm{Y}_{1-x} \mathrm{Gd}_{x}\right\}_{3} \mathrm{Fe}_{5} \mathrm{O}_{12}$. The solid line indicates a relation of $n_{\mathrm{B}}=|21 x-5.0| \mu_{\mathrm{B}}$ and the experimental values are shown by solid circles (see text).

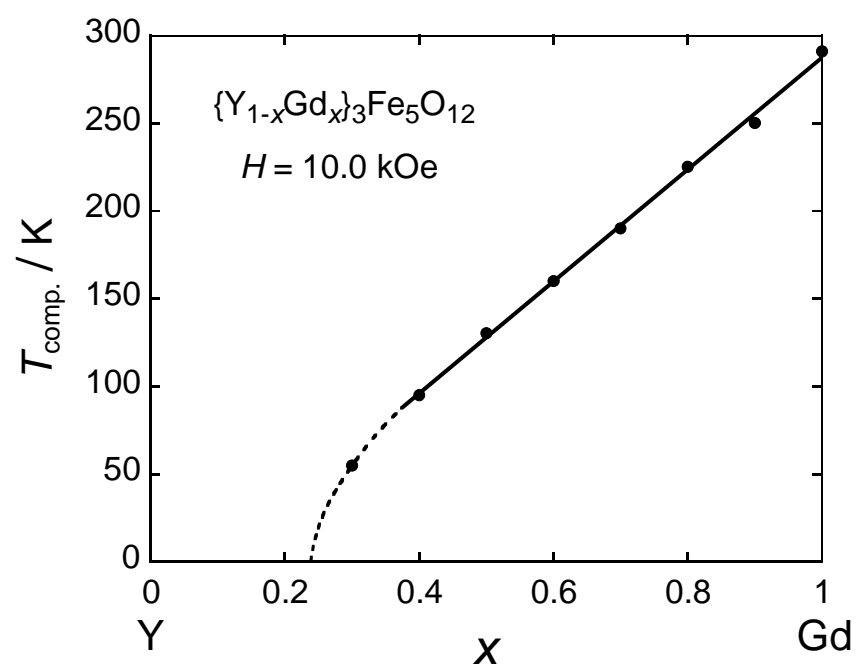

Figure 14. Concentration dependence of the compensation temperature for $\left\{\mathrm{Y}_{1-x} \mathrm{Gd}_{x}\right\}_{3} \mathrm{Fe}_{5} \mathrm{O}_{12}$. There is no compensation temperature for $x \leq 0.24$. 


\section{§ 4. SUMMARY AND REMARKS}

A systematic study of magnetic measurements has been made for $\left\{\mathrm{Y}_{1-x} \mathrm{Gd}_{x}\right\}_{3} \mathrm{Fe}_{5} \mathrm{O}_{12}$ over the wide temperature range 5.0 to $700 \mathrm{~K}$. Many results are presented in this report that extend to temperatures below $77 \mathrm{~K}$. The progressive variation of the three-sublattice ferrimagnetism is seen step by step. The variation of magnetization versus temperature given in figures 4 and 12, for various values of $x$ in $\left\{\mathrm{Y}_{1-x} \mathrm{Gd}_{x}\right\}_{3} \mathrm{Fe}_{5} \mathrm{O}_{12}$, reproduces that observed in the rare-earth iron garnet system $R_{3} \mathrm{Fe}_{5} \mathrm{O}_{12}$ ( $R$ is rare earth element) with varying $R$ (Pauthenet $1958 \mathrm{~b}$, Néel et al 1964). The changing $x$ in $\left\{\mathrm{Y}_{1-x} \mathrm{Gd}_{x}\right\}_{3} \mathrm{Fe}_{5} \mathrm{O}_{12}$ is quite similar to the changing $R$ in $R_{3} \mathrm{Fe}_{5} \mathrm{O}_{12}$. The magnitude of saturated magnetization at a certain given $T$ can be varied by changing $x$ in $\left\{\mathrm{Y}_{1-x} \mathrm{Gd}_{x}\right\}_{3} \mathrm{Fe}_{5} \mathrm{O}_{12}$ much easily than changing $R$ in $R_{3} \mathrm{Fe}_{5} \mathrm{O}_{12}$, from the view point of applications.

Magnetic investigations of garnet-oxides have been extensive in the decade from 1955 to 1965. The complete bibliography is listed in the references of Landolt-Börnstein, which reflects the richness and subtleties of the physical features in the garnets (Hellwege 1978). Recent fascinating investigations of garnets have been reported, emphasizing the low-temperature magnetic data through the progress and improvement of experimental instruments. There are some important reports, for example: the discovery of double peaks in $\mathrm{Ho}_{3} \mathrm{Fe}_{5} \mathrm{O}_{12}$ due to a phase transition (Nagata et al, 2001), the beautiful Van Vleck temperature-independent paramagnetic susceptibility of $\mathrm{Tm}_{3} \mathrm{Fe}_{5} \mathrm{O}_{12}$ (Awaka et al, 2003) and the abnormal susceptibility of vanadium garnets $\mathrm{AgCa} \mathrm{Co}_{2} \mathrm{~V}_{3} \mathrm{O}_{12}$ and $\mathrm{NaPb}_{2} \mathrm{Co}_{2} \mathrm{~V}_{3} \mathrm{O}_{12}$ (Nagata et al, 2005).

\section{REFERENCES}

Aléonard, R., 1960, J. Phys. Chem. Solids, 15, 167.

Anderson, E. E., Cunningham, J. R. Jr., and McDuffie, G. E., 1959, Phys. Rev, 116, 624.

Anderson, E. E., 1964a, Phys. Rev., 134, A1581 and references therein; 1964b, Proc. Intern. Conf. on Magnetism, Nottingham, 660.

Awaka, J., Endoh, R., and Nagata, S., 2003, J. Phys. Chem. Solids, 64, 2403.

Dionne, G. F., 1971, J. Appl. Phys., 42, 2142.

Geller, S., 1967, Z. Krist., 125, 1.

Harrison, G. R., and Hodges, L. R. Jr., 1962, J. Appl. Phys., 33, 1375.

Hellwege, K. H., 1978, Magnetic and other properties of oxides and related compounds. Part A: Garnets and Perovskites, edited by K. H. Hellwege, Landolt-Börnstein, New Series, Group3 (Crystal and Solid State Physics), Vol. 12, (Springer, Berlin), p1 and references therein.

Nagata, S., Sasaki, H., Suzuki, K., Kiuchi, J., and Wada, N., 2001, J. Phys. Chem. Solids, 62, 1123.

Nagata, S., Yamagishi, T., Awaka, K., Awaka, J., Ebisu, S., and Chikazawa, S., 2005, J. Phys. Chem. Solids, 66, 177.

Néel, L., Pauthenet, R., and Dreyfus, B., 1964, Progress in Low Temp. Phys., 4, 344.

Pauthenet, R., 1956, Compt. Rend., 243, 1499.

Pauthenet, R., 1958a, J. Appl. Phys., 29, 253; 1958b, Ann. Phys. (Paris), 3, 424.

Vassiliev, A., Nicolas, J., and Hildebrandt, M., 1961, Compt. Rend., 252, 2529. 